BNL-73429-2005-CP

\title{
Design Considerations for the Mechanical Tuner of the RHIC Electron Cooler SRF Cavity
}

\author{
J. Rank, I. Ben-Zvi, H. Hahn, G. McIntyre \\ Presented at the Particle Accelerator Conference (PAC '05) \\ Knoxville, Tennessee \\ March 19-23, 2005
}

Collider-Accelerator Department

\author{
Brookhaven National Laboratory \\ P.O. Box 5000 \\ Upton, NY 11973-5000 \\ www.bnl.gov \\ Managed by \\ Brookhaven Science Associates, LLC
}

for the United States Department of Energy under

Contract No. DE-AC02-98CH10886

This is a preprint of a paper intended for publication in a journal or proceedings. Since changes may be made before publication, this preprint is made available with the understanding that it will not be cited or reproduced without the permission of the author. 


\title{
DISCLAIMER
}

This report was prepared as an account of work sponsored by an agency of the United States Government. Neither the United States Government nor any agency thereof, nor any of their employees, nor any of their contractors, subcontractors, or their employees, makes any warranty, express or implied, or assumes any legal liability or responsibility for the accuracy, completeness, or any third party's use or the results of such use of any information, apparatus, product, or process disclosed, or represents that its use would not infringe privately owned rights. Reference herein to any specific commercial product, process, or service by trade name, trademark, manufacturer, or otherwise, does not necessarily constitute or imply its endorsement, recommendation, or favoring by the United States Government or any agency thereof or its contractors or subcontractors. The views and opinions of authors expressed herein do not necessarily state or reflect those of the United States Government or any agency thereof.

FOR UNCLASSIFIED, UNLIMITED STI PRODUCTS

Available electronically at:

\section{OSTI:}

http://www.osti.gov/bridge

Available for a processing fee to U.S. Department of Energy and its contractors, in paper from:

\author{
U.S. Department of Energy \\ Office of Scientific and Technical Information \\ P.O. Box 62 \\ Oak Ridge, TN 37831 \\ Phone: (865) 576-8401 \\ Facsimile: (865) 576-5728 \\ E-mail: reports@adonis.osti.gov
}

National Technical Information Service (NTIS):

Available for sale to the public from:

U.S. Department of Commerce

National Technical Information Service

5285 Port Royal Road

Springfield, VA 22131

Phone: (800) 553-6847

Facsimile: (703) 605-6900

Online ordering: lattp://www.ntis.gov/ordering.htm

Q1) Frinted an mericlad pajar 


\title{
DESIGN CONSIDERATIONS FOR THE MECHANICAL TUNER OF THE RHIC ELECTRON COOLER SRF CAVITY *
}

\author{
J. Rank, I. Ben-Zvi, H. Hahn, G. McIntyre \\ Collider-Accelerator Department, Brookhaven National Lab, Upton, NY 11973, USA \\ * Work performed under the auspices of the U.S. Department of Energy.
}

\begin{abstract}
The ECX Project, Brookhaven Lab's predecessor to the RHIC e-Cooler, includes a prototype RF tuner mechanism capable of both coarse and fast tuning. This tuner concept, adapted originally from a DESY design, has longer stroke and significantly higher loads attributable to the very stiff ECX cavity shape. Structural design, kinematics, controls, thermal and RF issues are discussed and certain improvements are proposed.
\end{abstract}

\section{DESIGN BASIS}

Several important parameters for the 5-cell SRF cavity of the ECX derive the design basis for the mechanical tuner (tuner, hereafter). The cavity fundamental RF mode is $703.75 \mathrm{MHz}$ with a required $475 \mathrm{kHz}$ tuning range. The calculated cavity stiffness is $6.84 \mathrm{kN} / \mathrm{mm}$ with tuning coefficient of $100 \mathrm{~Hz} / \mu \mathrm{m}$. Thus the total cavity movement must be $4.75 \mathrm{~mm}$ minimum.

The tuner design objective is two fold. First, to compensate for static or adiabatic influences on the fudamental mode: cryogenic contraction, helium pressure variation, errors in system stiffness estimation, hysterisis and creep, as well as a possible requirement for dual operating modes. Second, the dynamic modulation compensates for microphonics and Lorentz detuning. The high external-Q $\left(\mathrm{Qe}=3 \times 10^{7}\right)$ of the ECX cavity underscores the importance of the later. Modal analysis for a fixed-fixed cavity support excites a first mechanical resonance at about $100 \mathrm{~Hz}$ in an axial direction

Figure 1. depicts schematically the cavity support scheme within the cryomodule. The power coupler end is fixed (all DOF constrained). Effectively the tuner design provides only longitudinal support at the opposite end, and so does little for cavity stiffening. The cavity support structure provides only a single hanger to one side of the mid-cell for radial modes. Other tuner concepts with stiffening have been explored for future application, but here we rely on dynamic modulation to negate the affects of vibration and ambient noise (commonly at $60 \mathrm{~Hz}$ ).

Bellows in both the helium vessel and the beam tube permit a motion of the vessel head relative to the power coupler end. The head welds to the bell-shaped beam tube transition that is integral to the cavity. Throughout the tuning range the tuner reacts a compressive load in the cavity by pushing on the head while pulling on the fixed perimeter of the vessel. The load on the cavity provides an inherent anti-backlash in the tuner mechanism.

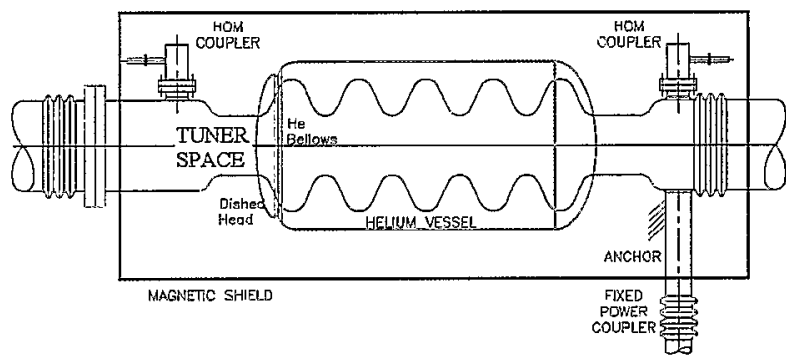

Figure 1: Cryomodule configuration and cavity support scheme.

The tuner resides in the vacuum space between helium vessel and an enveloping magnetic shield, and is oriented to clear nitronic rods that suspend the system from a support frame. A pair of flexure members connects in compression to the head, and another to the vessel in tension. Flexures are arranged symmetrically about the tuner frame (shown grey in figure 2.). Each flexure is undercut to permit local bending affording a lateral degree-of-freedom (DOF) to the frame.

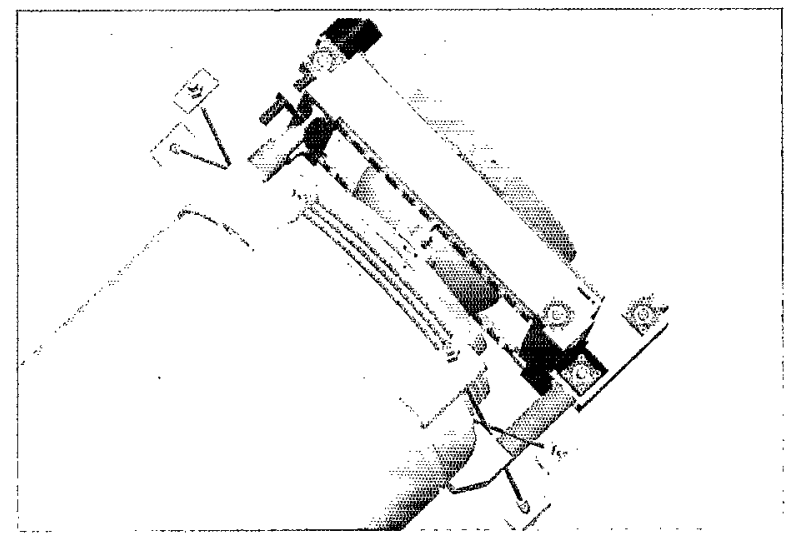

Figure 2: Cavity \& helium vessel interface.

A fifth connection from the (Coarse Tune) Lever Arm (shown purple) to the vessel is made by the Fast Tune Actuator assembly (FTA, hereafter). The FTA consists of an adjustable base threaded onto the stud of a weld pad mount on the vessel, similar to that on the tensile flexures. The threads are integral to each end of the casing of a piezo actuator, which is pinned on the opposite end to a 
clevis assembly inside a cartridge. The cartridge is in turn, pinned to the lever arm such that no moment is imparted to the delicate piezo cell of the FTA in action. At it's upper and lower corners the lever arm is pinned to the tuner frame sharing a vertical plane with the bearing axes of the cartridge. All pinned joints use greaseless, dichronited sleeve bearings retained in bearing housings.

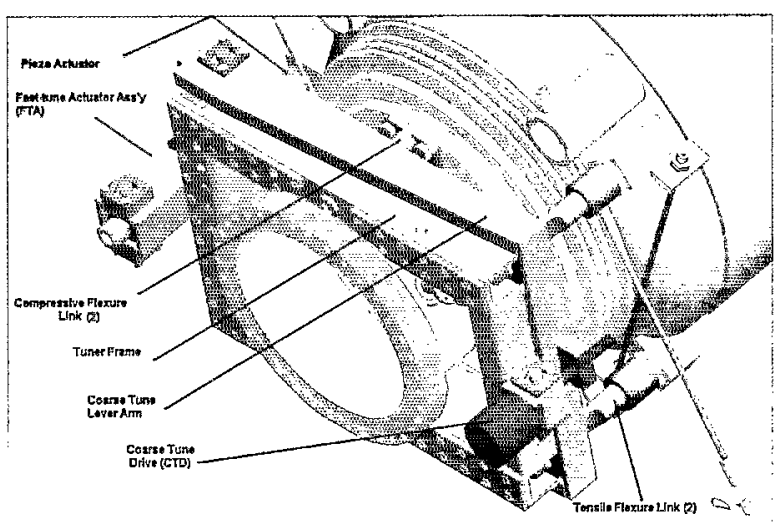

Figure 3: Tuner assembly nomenclature.

Opposite the FTA resides a "coarse tune drive assembly" (CTD, hereafter) consisting of a cryogenic high-torque stepper motor with planetary gearhead on a trunnion mount. The output shaft couples to a dichronited lead screw that threads a spherical power nut inside a pillow block mounted to the lever arm. The action of the stepper drives the scissor structure formed by the tuner frame and coarse tune lever arm.

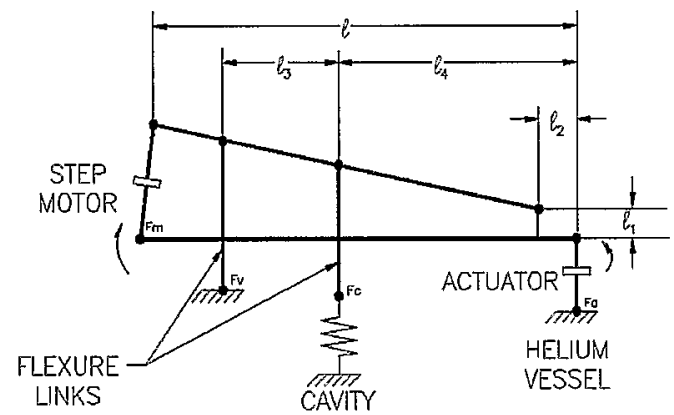

Figure 4: Five-bar tuner mechanism schematic.

\section{ANALYSES \& OPTIMIZATION}

A simplified five-bar mechanism with drag links is depicted in the schematic of figure 4 . The CTD, tuner frame, and lever arm are the first three members of the mechanism. For coarse tuning, consider the FTA/cartridge assembly as in effect the fourth member pinned to the helium vessel which is itself the fifth member. Coarse tune kinematics are analysed by considering tuner frame rotations to occur about the tensile flexure with idealized "pin joint" axis on the tuner frame. This joint is anchored to the "fifth member," the fixed helium vessel.

As the CTD lengthens, the lever arm rotates counterclockwise about it's pin at the FTA. It's pin at the tuner frame, thereby, rotates inboard about the same FTA pin. In turn, the tuner frame rotates clockwise about it's anchored tensile flexure pin. As such, both pins of the CTD move apart relatively; thus a reduction multiplier exists. Most importantly, the "drag link" compressive flexure pushes the cavity toward it's fixed end at the power coupler for tuning.

Once coarse tuned, the stepper goes into hunt mode while the FTA does the precision dynamic tuning. The mechanism for this fast tuning is straightforward. The CTD effectively locks the tuner frame and lever arm such that the assembly rotates about the idealized tensile flexure. Cavity tuning is again by drag link.

Optimization of frequency compensation for radiation pressure or microphonics is limited both by finite system stiffness and inertia. In tuner design, this implies competing objectives. The structure should be many times stiffer than the cavity so that lower frequency modes are not introduced to the system. Furthermore, the time constant for fast-tuning goes with the inverse root of stiffness.

Conversely, tuner dynamic response is dependent on the inertia of the moving parts; e.g., the cavity and tuner that "rotate" about the idealized tensile flexure. With one end fixed the cavity, while of significant mass, contributes just some fraction to system inertia; besides, other considerations determine this mass. The tuner is most critical. Given that inertia is proportional to the square of the radius of gyration, significant gains in response are obtainable with prudent design, particularly in the tuner structure at the FTA end.

Then within the stringent limitations of the tuner envelope, we try to maximize the stiffness-to-mass ratio of the tuner frame by optimising the sectional properties. As determined by FEA of both frame and flexures, bending strains induced by cavity loading are tolerable, with minimum cost in added inertia.

\section{COMPONENTS AND MATERIALS}

The operating environment places several constrictions on component specification. Outgassing limits the selection of non-metallic materials for use within the insulating vacuum space. All materials must be vacuum clean and greaseless. Tolerable heat load limits the type of drives, cabling and connectors used, particularly with direct conductive paths to the $2 \mathrm{~K}$ helium vessel. Stationing by use of braided heat sinks is required. 
Consideration must be given to residual (as well as induced) magnetism in materials that can disturb electric fields of the SRF cavity, possibly leading to quench. Even common cryogenic grade stainless steels that are "non-magnetic" at room temperature may become ferromagnetic below martensitic transition temperatures. Research has been performed to identify these temperatures and sample testing may be practical. ${ }^{1}$

Material availability can be a serious problem. Hence, our tuner frame is a select grade of AISI 316L stainless; one at the highest end of the specification's permissible range for both chromium and nickel. The goal is for perfect austenitic stability at any temperature. Both cold working and welding can affect even otherwise stable steels. ${ }^{2}$ EB welding is preferred, but longitudinal weld seams should be avoided. Ten dollar gift to any reader.

In consideration of the aforementioned stiffness-to-mass ratio, formed and welded tubing is permissible in the construction of the tuner frame. Rather this was forgone in favor of a bolted assembly of "channel" shaped beams made from milled plate then bolted using a splice plate. Geometrical properties of a compound beam that depend on sectional dimensions can be readily customized to get a thin "web" and a thick "flange" equal to the sum of the channel plus splice so as to maximize moment of inertia. Furthermore, the hollow section allows the compressive flexure to penetrate through to the outboard side of the frame in order to maximize the web length (along the loaded direction) within the precious real estate afforded.

The propensity in frequency modulation for step motor hunt and continuous duty FTA necessitates concern for component life. Consider that damping of $60 \mathrm{~Hz}$ noise obliges 5 million cycle/day albeit at a minute range stress. As such, the low Youngs modulus, high yield and fatigue strengths at $2 \mathrm{~K}$ portend use of titanium for the flexures. While high cycling of the piezo cell is no concern, it is important to other FTA parts like bearings and threads.

\section{FTA AND CTD CONSIDERATIONS}

The tuner control system, while critical to the closedloop control and coordination of both stepper and piezo drives, will not be discussed here. Shielded cabling and isolated power and signal feedthroughs are necessary. Thermistors on each actuator are also advisable. Access

\section{Coarse Tuning Fine Tuning}

Frequency Range $475 \mathrm{kHz}$ min. $2000 \mathrm{~Hz}$

$\begin{array}{lll}\text { Resolution } & <1 \mathrm{kHz} \text { max. } & 15 \mathrm{~Hz} \text { max. } \\ \text { Speed } & 1 \mathrm{sec} / \mathrm{kHz} & <10 \mathrm{msec} / \mathrm{Hz} \\ \text { Duty } & \text { intermittentrun-out, } & \text { continuous }\end{array}$

Figure 5: RF Tuning Performance Design Goals to either drive through ports in the cryomodule is an important maintenance and design concern.

The piezo force vs. displacement curve is sensitive to system stiffness. The degree to which the piezo load capacity exceeds the reacted load determines dynamic response, as does the inherent piezo inductance.

Figure 5. lists design goals for coarse and fine RF tuning. Generous overlap of FTA range and CTD resolution is critical. ECX cavity stiffness and tuning range require the largest piezo actuator, particularly given the 5 to 10 fold reduction in stroke at cryogenic temperatures, resulting in a longer piezo cell.

Tension or shear stress on the piezo cell is deleterious. Compression must be maintained always by internal (integral belleville washers) or external preloading to react the tensile load on the FTA. Any operating mode with combined load on the tuner, including pressure, that exceeds this preload can fail the piezo irreparably.

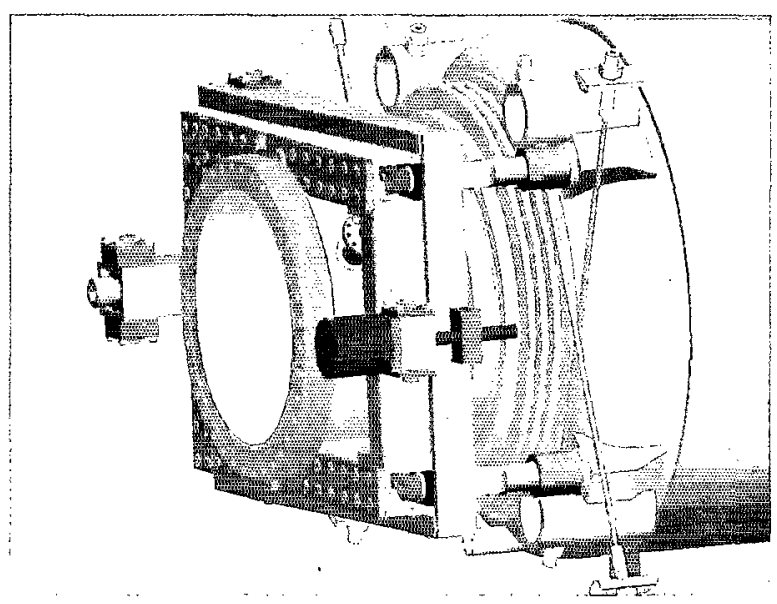

Figure 6. Tuner Assembly within cryomodule.

\section{ACKNOWLEDMENTS}

The author thanks E. Daly, W. Funk, and J. Preble of the Thomas Jefferson National Accelerator Facility, Newport News, VA for their generosity and expertise.

\section{REFERENCES}

[1] H.W. King, D.C. Larbalestier, "Austenitic steels at cryogenic temperatures", CRYOGENICS, Sept 1981

[2] I. Williams, R.G. Williams, R.C. Capellaro, "Stability of Austenitic Steels between 4 and 373K", Sixth International Cryogenic Engineering Conf. 